\title{
ANÁLISE DE PROJETO GRÁFICO DE LIVROS INFANTIS DIGITAIS
}

\author{
Graphic design analysis of digital children's books
}

\section{KOCH, Gisele Souza I Graduada em Design Gráfico}

Universidade Estadual de Londrina

gisele.skoch@gmail.com

\section{TOZATTI, Danielle De Marchi I Mestre em Ciências Sociais}

Universidade Estadual de Londrina

daniellemarchi@yahoo.com.br

\section{Resumo}

A popularização das novas tecnologias digitais abriu um novo campo de atuação para o designer gráfico. Os livros infantis, que já apresentam interação na mídia impressa agora se encontram nesses novos suportes que expandiram as possibilidades sensoriais, reunindo visão, audição e tato em uma experiência nova de leitura. A partir de uma reflexão teórica inicial, este trabalho analisa três livros infantis digitais, a fim de identificar os elementos de design e suas funcionalidades dentro dos projetos gráficos destes livros.

Palavras-chave: Livro Infantil. Design. Projeto Gráfico. Livro Digital.

\section{Abstract}

There is now a new work field for graphic designers because of the new digital technologies that have become popular. Printed children's books often make use of interaction, but the new media expanded sensorial possibilities, gathering vision, hearing and touching in a new reading experience. A theory-based study will support a critical analysis of three digital books to identify design elements and its functions in these books' graphic projects.

Keywords: Children's book. Design. Graphic Project. Digital book. 


\section{INTRODUC̣ÃO}

O livro digital transformou o mercado editorial. Ele apresenta diferenças de custo e acesso em relação ao livro impresso. Entretanto, sua entrada e consolidação não erradicou o comércio de impressos, apenas modificou a relação de consumo.

As adaptações do livro do meio tradicional para essa nova mídia se dão não apenas na maior gama de interatividade que ela proporciona, mas também na apresentação e visualização do livro. Antes opaco e projetado com elementos e espaços adequados para impressão, agora é iluminado, tem um manuseio diferente, e por todos esses motivos deve ser repensado graficamente.

Agora, o livro digital pode ser lido através de vários suportes eletrônicos: computadores, eReaders, tablets, e smartphones são os principais exemplos. Entre esses, os tablets têm ganhado muito espaço por serem multitarefas, diferente dos eReaders, e por terem um tamanho, preço e peso intermediário entre o computador e o smartphone - o primeiro muito grande, o segundo muito pequeno.

No universo dos livros digitais há o espaço para o livro infantil. Existe curiosidade e um crescente acesso de crianças a essas tecnologias. Mike Shatzkin (2010), consultor editorial norte-americano, acredita que "como os aparelhos ficam mais baratos e mais ubíquos, pais e filhos vão aprender rapidamente como as experiências interativas podem ser divertidas, instrutivas e acessíveis".

Esses pequenos leitores estão sendo ou ainda serão alfabetizados, e provavelmente sendo incentivados a se interessar por livros. Durante o desenvolvimento, a criança busca desafios para ampliar sua capacidade cognitiva.

O Design Gráfico é essencial na proposta de desenvolvimento do livro digital, pois é através dele que a transição para essa mídia pode ser projetada de maneira que as vantagens dos suportes virtuais sejam aproveitadas ao máximo e os possíveis obstáculos sejam solucionados.

Os conhecimentos e princípios de design potencializam o interesse pela leitura do livro infantil digital, e também possibilita planejar os níveis de interatividade da ilustração com o leitor nos âmbitos da visão, audição e tato.

Se o livro digital há cinco anos mal existia, hoje é ampla e rapidamente produzido, comercializado e inovado. A mídia virtual amplia em proporções geométricas as possibilidades. 
O acesso e curiosidade de tablets e smartphones por crianças apresentam a oportunidade de projetar o livro infantil e adequá-lo a esses novos meios. Este trabalho pretende associar a importância do projeto gráfico com o interesse na instalação de um livro digital.

Para isso, será apresentado um referencial teórico sobre o que é a literatura infantil ou que características a determinam, sobre qual é a geração de leitores do livro digital e o que essa tecnologia pode determinar em seu comportamento e, por fim, sobre quais elementos de Design Gráfico devem ser considerados e estudados para um projeto de livro infantil digital. Estabelecidas essas bases conceituais, serão apresentados três exemplos de livros infantis digitais para que seu projeto gráfico seja analisado.

\section{Sobre a literatura infantil}

Meireles (1984), ao refletir sobre o livro ideal para a criança, conclui que tal livro somente pode ser classificado como adequado se a própria criança o elege. Apesar de o autor procurar se aproximar da infância ao escrever o livro e essa ser uma difícil tarefa, pois a vivência faz a sensibilidade e ingenuidade esvaírem-se, está na criança a capacidade de classificar uma literatura infantil como adequada, desde que a literatura emocione, encante a criança.

Existem livros infantis que hoje são assim classificados, entretanto sua produção não se destinou a crianças, a princípio: "Robinson Crusoé" e "Os Três Mosqueteiros", de Daniel DeFoe e Alexandre Dumas, respectivamente, e "Viagens de Gulliver", de Jonathan Swift, por exemplo. O oposto também pode ocorrer, quando um livro classificado como infantil toma o interesse de adultos. É o caso da ficção de Tolkien, "O Hobbit", que premiado como um livro infantil atrai a leitura de muitos adultos.

Coelho (1997), Palo e Oliveira (2006) concordam que a literatura infantil é aquela que em sua concepção foi destinada à criança. Entretanto, Meireles (1984) acredita que nem sempre essa literatura realmente atinge o pequeno leitor, no sentido de entretê-lo. A autora acredita que a literatura infantil é aquela que a criança lê com prazer. Não há, assim, uma "Literatura Infantil a priori, mas a posteriori" (MEIRELES, 1984, p. 20, grifos da autora). Os livros classificados como infantis nem sempre têm em seu conteúdo uma literatura, de fato. Não é a presença da palavra escrita que define o livro como literário.

A variedade de estilos de textos para o livro infantil é imensa. Apesar disso, Linden (2011, p. 57) explica que devido à predominância das imagens, todos os textos acabam sendo em sua maioria breves. Essa brevidade colabora com 
a "unidade de sentido" do texto de determinada página com a correspondente ilustração. Existem também livros em que o texto não se encontra em sua forma escrita (livros-imagem). O texto desses livros deve ser inventado pelo leitor a partir da sequência de ilustrações que narram visualmente a história através das páginas.

Coelho (1997) considera que a etapa de desenvolvimento da criança é um fator importante na classificação do livro, em termos de adequação ao leitor, afinal o grau de conhecimento e amadurecimento é determinante para que a criança compreenda e identifique-se com o texto. Entretanto, isso não é algo arbitrário, pois as relações entre faixas etárias e desenvolvimento cognitivo são aproximativas. Isso porque os fatores do desenvolvimento da criança não se limitam à faixa etária e englobam outros aspectos, como o meio em que a criança se desenvolve.

E o meio atual é repleto de tecnologia. E conviver e desenvolver-se em meio a tal tecnologia certamente modifica os processos cognitivos e perceptivos da criança.

\section{Os leitores: nativos digitais}

Cada geração apropria-se e transforma os objetos da cultura humana de seu tempo (MELLO, 2007). A mais nova geração de crianças nasceu e está crescendo em meio a uma nova tecnologia. Os leitores anteriormente citados são dessa geração íntima com computadores, gadgets e games. Segundo Prensky (2001a), isso certamente influencia no modo de aprender e na maneira de pensar e se expressar dessas crianças. $\mathrm{O}$ autor as denomina nativos digitais, e acrescenta que os que não nasceram cercados desta tecnologia devem a ela se adaptar, pois não há uma maneira de retornar aos velhos métodos de pensamento.

Em entrevista à Revista Pátio, que trata de educação, o pesquisador em neurociência Ramon Cosenza (2011) diz que há uma diferença no processamento de informações visuais das crianças nativas digitais. Tal processo se dá mais rapidamente do que se dava nas crianças anteriores a essa geração. A memória operacional também se apresenta melhor, pois elas conseguem envolver-se em multitarefas com facilidade.

Essas mudanças influenciam na comunicação entre as células nervosas, e a facilidade de comunicação neuronal, que facilita o processamento de imagens, faz com que a criança se interesse e se estimule pelas imagens, em detrimento do texto impresso: "acostumados a um mundo repleto de imagens que se modifica constantemente, sentem-se confortáveis quando interagem 
com conteúdos apresentados dessa forma, enquanto o texto impresso já não tem o mesmo encanto para eles" (COSENZA, 2011).

Prensky (2001b) afirma que pesquisas na área da neurobiologia confirmaram que o cérebro humano pode modificar-se fisicamente por estímulos externos. As estruturas do cérebro são plásticas e podem mudar ao longo de toda a vida.

As crianças nativas digitais, devido às mudanças de estrutura causadas pelas tecnologias, podem se apresentar desatenciosas às formas antigas de aprendizado. E isto se reflete em outras atividades. Porém, não significa que em todos os âmbitos o espaço de tempo de atenção dessas crianças seja curto. Para jogos, por exemplo, elas podem depositar um espaço de tempo de atenção muito longo. "As diferenças cognitivas dos Nativos Digitais clamam por novas abordagens de educação que se 'encaixem' melhor" (PRENSKY, 2001b, p.5, tradução nossa').

\title{
Projeto Gráfico para o meio digital
}

Projeto Gráfico compreende todas as decisões tomadas na construção de uma peça gráfica. Quem manuseia, usufrui e experimenta o material construído utiliza outros sentidos além da visão. Olfato, audição e tato podem contribuir para uma experiência mais prazerosa quando se manuseia ou lê um livro. O "corpo" do livro - sua matéria, deve acompanhar e refletir sua "alma" conteúdo (MORAES, 2008).

\begin{abstract}
Assim, ler um livro ilustrado não se resume a ler texto e imagem. É isso, e muito mais. Ler um livro ilustrado é também apreciar o uso de um formato, de enquadramentos, da relação entre capa e guardas com o seu conteúdo; é também associar representações, optar por uma ordem de leitura no espaço da página, afinar a poesia do texto com a poesia da imagem, apreciar os silêncios de uma em relação à outra... Ler um livro ilustrado depende certamente da formação do leitor. (LINDEN, 2011, p. 9).
\end{abstract}

O livro de literatura, como parte da cultura e história humana deve possuir uma narrativa sedutora, desejável. Lins, em 2003, quando o livro digital não se apresentava ainda muito conhecido e disseminado, previa que a Internet

1 Texto original: The cognitive differences of the Digital Natives cry out for new approaches to education with a better "fit" 
possibilitaria uma evolução, pois a capacidade de participação do leitor com este novo livro torna-se muito interessante: visualização de animações, inclusão de jogos e sons, entre outros.

No presente, o livro digital está pulsando. Lins e Silva (2013) acredita que haverá uma mudança na apresentação do livro digital, que ainda se mostra muito parecido visualmente com o impresso. "A questão não é o formato, mas o que a leitura, que exige concentração, significa para uma geração que interage ativamente, o tempo todo, com o que encontra nos suportes digitais". (LINS E SILVA, 2013).

Muitas recomendações e princípios utilizados para o impresso caem por terra, pois a dinâmica de leitura no ambiente digital não é mais linear, e sim multidimensional. Mas podem servir de guia para refletir sobre um projeto de livro digital, pois continua livro em essência.

O livro é um objeto de contemplação estética, físico e sensorial. Design e ilustração articulados podem multiplicar sentidos e compreensões no livro. "A atenção aos aspectos plásticos de um livro não se justifica somente no auxílio à competição e à concorrência [...]. Tal esmero com o gráfico é para inserir a eternidade do livro na contemporaneidade - esta é a sua função maior" (OLIVEIRA, 2008, p. 45).

A seguir, serão apresentados aspectos gráficos essenciais que devem ser estudados e levados em consideração na produção de um livro digital infantil.

\section{Cores}

Um dos primeiros tópicos a respeito de cores a se considerar é o fato de elas se comportarem de maneira diferente dependendo do observador, de qual é o suporte de visualização (papel, tinta, tela, tecido) ou a fonte (luz ou pigmento). No caso do livro digital, no qual o suporte é uma tela, a cor é apresentada através de luz. A cor da luz é aditiva: as cores primárias somadas resultam em uma cor mais clara: o branco. A não presença de cores-luz resulta no preto (FRASER; BANKS, 2011).

Fraser e Banks (2011) explicam como a cor é representada em um sistema de computador: as informações das imagens são armazenadas em um sistema RGB de 24 bits. Como as cores são visualizadas em diferentes telas com diferentes intensidades de iluminação, qualidade, emissores de luz - pode haver uma variação da fidelidade da cor que não é controlável.

Além desses fatores externos ao indivíduo, a percepção da cor pode variar devido à cultura, psicologia, história e individualidade. 
"A percepção da cor é uma forma de comunicação. A cor está na linguagem, isto é, faz parte do código necessário à base desta comunicação" (SILVEIRA, 2010, p.40). A percepção da cor não se limita apenas a um processo fisiológico. As cores são simbólicas, elas têm relação com a linguagem e com a comunicação. Assim, não é apropriado incluir cores em um projeto de maneira sortida ou não intencional.

Pedrosa (2004) diz que as cores são sensações - fisiológicas e subjetivas, as cores causam emoções diferentes. Farina, Peres e Bastos (2006) consideram que existe a cultura e a psicologia individual diferem a preferência de cores entre as pessoas. Os autores ainda apontam que a idade influencia na percepção das cores, já que a visão sofre mudanças de acordo com a idade do indivíduo. Crianças costumam preferir as mais puras e brilhantes, e nos primeiros meses de vida enxerga muito bem o amarelo, vermelho e o verde. $\mathrm{O}$ azul é uma cor que vai subindo na escala de preferência de acordo com a idade do indivíduo.

As cores individualmente provocam sensações diferentes. Quando combinadas, as sensações podem se modificar acentuando-se, atenuando-se ou mudando completamente. Ao referir-se ao uso das cores no livro ilustrado, Rui de Oliveira (2008, p.51) afirma:

\begin{abstract}
Somente quando [a cor] se relaciona com a luz, com a sombra, com o momento psicológico dos personagens ou com o atmosférico da cena representada, ela realmente alcança sua plenitude expressiva. Logo, a cor deve ser analisada a partir de sua relação com as outras cores.
\end{abstract}

Farina, Peres e Bastos (2006) apresentam uma lista de cores e suas sensações polarizadas - ora positivas, ora negativas. Entretanto, a essência é sempre muito parecida: o vermelho, por exemplo, representa força, vivacidade, agressividade ou amor. Essas sensações podem ser classificadas como boas ou ruins, entretanto são todas dotadas da energia e vivacidade do vermelho, que na natureza se apresenta como sangue, fogo, ou algum alimento venenoso ou picante, ou doce.

A luminosidade da cor também causa diferentes sensações: As cromáticas provêm das cores, e as acromáticas provêm da iluminação. Fraser e Banks (2011) afirmam que pelas características psicológicas e sensações provocadas pelas cores, elas devem ser escolhidas de modo a confirmar e ressaltar a mensagem contida em que estiverem. 


\section{Tipografia}

Tipografia refere-se à forma, uso e composição das letras. A princípio a tipografia era projetada para o meio impresso. Hoje, o meio digital apresenta um universo de possibilidades e eliminação de preocupações antes tidas ao imprimir tipos. E, ao mesmo tempo, traz novos obstáculos ou questões a serem resolvidas (BERGSTRÖM, 2010). O texto e a tipografia também são imagens. Assim, portanto, podem apresentar personalidade e causar sensações.

A tipografia é o meio pelo qual uma ideia escrita recebe uma forma visual. A seleção da forma visual pode afetar significativamente a legibilidade da ideia escrita e as sensações de um leitor em relação a ela devido às centenas, se não milhares de fontes disponíveis. A tipografia pode produzir um efeito neutro ou despertar paixões [...] (AMBROSE; HARRIS, 2009, p.57, grifo nosso).

Para Bringhurst (2005) a tipografia deve respeitar todo o projeto a que se destina. Ao mesmo tempo em que deve chamar atenção para que o texto não passe despercebido, deve abdicar dessa atenção para ser lida.

Se a tipografia é um elemento visual, suas características funcionais e estéticas devem ser levadas em consideração antes da escolha. Bringhurst (2005) recomenda que na escolha da tipografia considere-se o meio para qual o tipo foi originalmente projetado, a adequação à tarefa e ao assunto do projeto, e o meio no qual o texto será lido.

Willberg e Forssman (2007) listam alguns cuidados ao utilizar tipos em telas: não criar linhas de texto muito longas, utilizar letras muito pequenas, tipos pouco legíveis, muito texto e quebras de linha incorretas. Tais problemas citados acima podem aumentar consideravelmente o cansaço de leitura provocado pela luz da tela. Os autores destacam ainda que a tipografia para a tela deve ser mais robusta que a impressa. Contrastes fortes, tipos finos ou espessos em excesso podem causar confusão entre os caracteres e perder a legibilidade, pois a tela pode causar difusão nos tipos.

As tipografias sem serifa são muito comuns no meio digital, certamente porque não possuem os detalhes de variação de espessura ou as próprias serifas - interessantes para textos curtos. Elas foram criadas no final do século XIX e no século XX e muito difundidas pelo caráter funcionalista defendido nos movimentos das primeiras décadas do século.

[...] há boas razões para se preferir as sem serifas às romanas. Os designers sentem que a utilidade das fontes

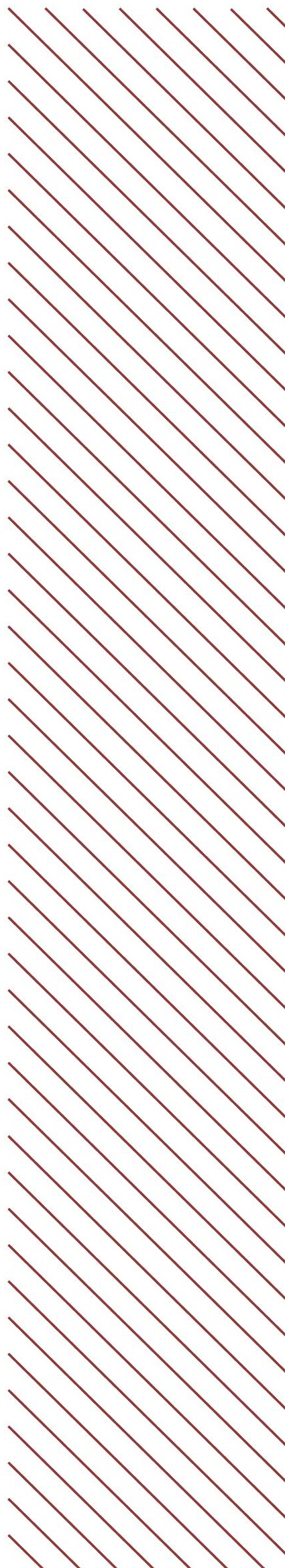


romanas é muito limitada em tamanhos pequenos, como abaixo de 13 pontos. As telas fortes, brilhantes e de baixa resolução fundem os traços finos, e as serifas são convertidas em blocos desproporcionais que distorcem os caracteres, gerando uma massa desordenada de texto (BERGSTRÖM, 2010, p. 106).

Embora no livro digital o texto não seja grande e exista a possibilidade de ouvir a história ao invés de ler, é importante que haja essa preocupação porque o texto ainda é parte gráfica do livro e encontra-se muitas vezes como suporte explicativo das interações do livro, ou no menu inicial, por exemplo.

\section{Diagramação}

A disposição dos elementos do livro é dependente do formato determinado para tal. Nos livros impressos, a princípio, podem-se classificar dois tipos de formato predominantes: o vertical e o horizontal. O livro com o formato vertical é o mais corriqueiro. É denominado "à francesa". Nesse tipo as imagens geralmente apresentam-se isoladas, independentes umas das outras. O livro com o formato horizontal ("à italiana") contribui para uma linearidade das imagens, "favorecendo a expressão do movimento e do tempo, e a realização de imagens sequenciais" (LINDEN, 2011, p. 53).

Em tablets e smartphones, a dimensão limita-se à da tela, entretanto o formato varia entre vertical e horizontal, pois tais dispositivos permitem a adaptação da tela ao que quem usa preferir, ou de acordo com o que é melhor de acordo com o aplicativo em questão (vídeos são mais bem visualizados na horizontal, por exemplo). No meio digital não há pagina dupla - caracterizada pela visualização da junção das páginas de um livro impresso - a não ser que se simule graficamente. Assim, algumas convenções na diagramação de livros impressos determinadas pela página dupla não se aplicam ao meio digital.

Linden (2011) divide a diagramação de textos e imagens no livro em quatro tipos:

- Dissociativa: determinada pela página dupla, essa diagramação divide texto em uma página e imagem em outra.

- Associativa: o texto é encaixado na mesma página da imagem, entretanto possui um espaço reservado e delimitado para si.

- Compartimentada: o texto é dividido em várias caixas ou balões, em uma disposição similar à de histórias em quadrinhos.

- Conjunta: oposta à dissociativa, esta diagramação integra o texto e a 
imagem. Ambos articulam-se em um espaço e linguagem próximos.

Linden (2011) dá uma atenção especial ao último tipo de diagramação. Nele, a narrativa passa a ter uma organização totalmente nova e mais poética. Entretanto, é importante frisar que ela se refere ao livro ilustrado impresso.

\section{Análise gráfica de livros infantis digitais}

Foram selecionados três livros para esta pesquisa e a justificativa da escolha encontra-se na primeira descrição de cada um.

\section{Dragoberto}

Figura 1 - Tela inicial do livro "Dragoberto"

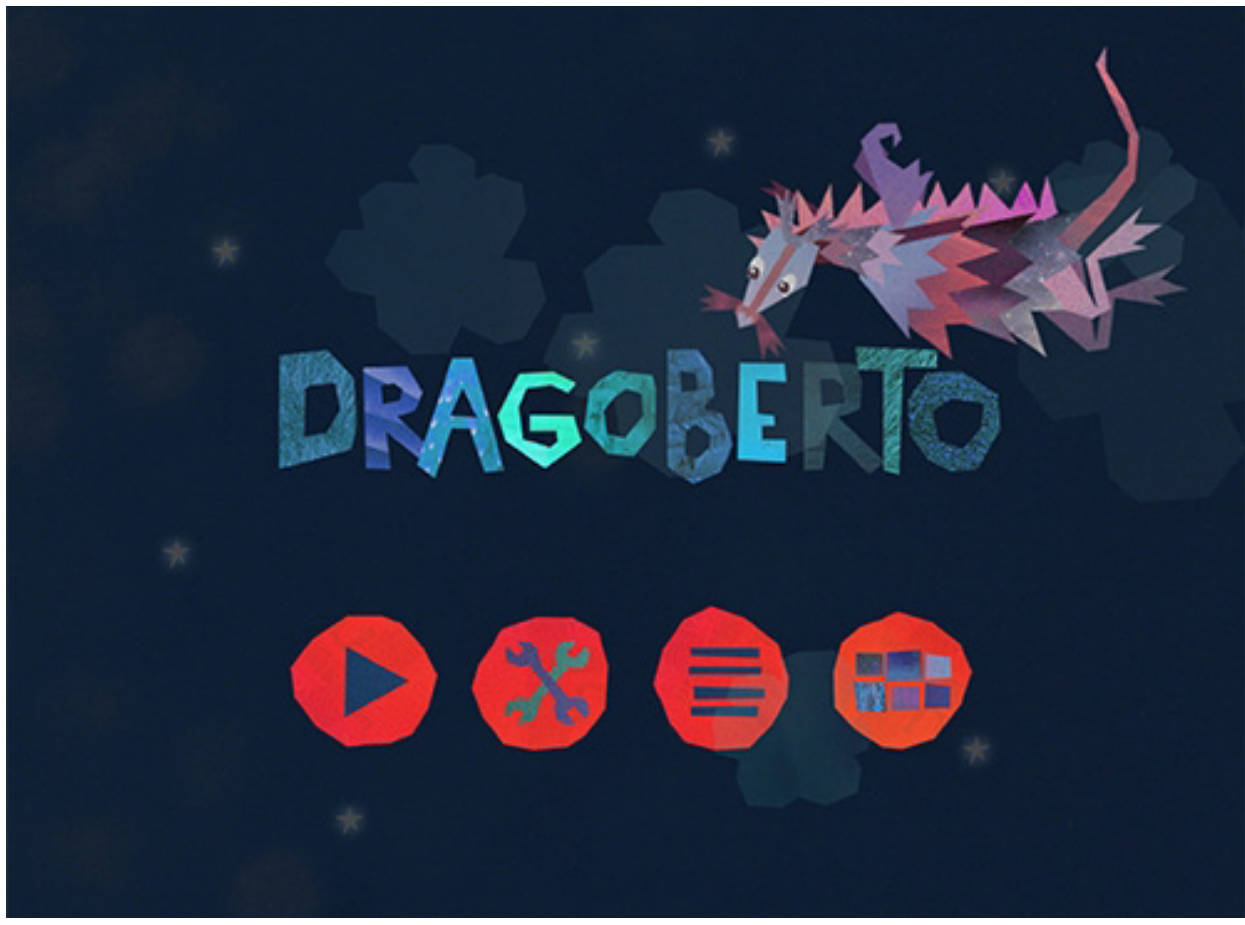

Fonte: Disponível em: br.dragoberto.com.

Esse livro é uma produção da Editora digital brasileira E-stilingue. A escolha de análise desse livro se dá por ser de origem nacional, e de ser disponibilizado apenas em um tipo de sistema operacional, o IOS. Apesar de não disponibilizar dados sobre o número de instalações, há um pequeno feedback positivo de alguns pais na página de downloads.

"Dragoberto" é o primeiro livro infantil da editora, que propõe interação audiovisual, equilibrando texto, imagem e som. Foi lançado em março de 2013 e até a conclusão desta pesquisa não recebeu atualizações. 
O livro tem 48 cenas em 14 páginas, textos e locuções em três línguas com opção de mais de uma língua ao mesmo tempo, opção de ligar ou desligar os recursos de áudio. É recomendado para crianças a partir de quatro anos.

As interações são táteis e de áudio. É possível ajudar o dragão a voar, colorir, ajudar o dragão a desviar de raios da tempestade, entre outros. A técnica de ilustração é de recorte digital com texturas. A possibilidade de interação com o leitor é indicada através de setas.

A maioria das cores do cenário do livro são pouco saturadas e tendem a tons frios. Entretanto, há cores vivas que contrastam com o restante da ilustração e que indicam o que responde com interação ao ser tocado. A tipografia do livro é sem serifa e é tipo manuscrita, em caixa alta. O texto é diagramado independente das ilustrações, e encontra-se separado delas, já que é possível escolher ouvir a história ao invés de ler.

\section{Boa Noitinha}

Figura 2- Tela inicial do livro "Boa noitinha"

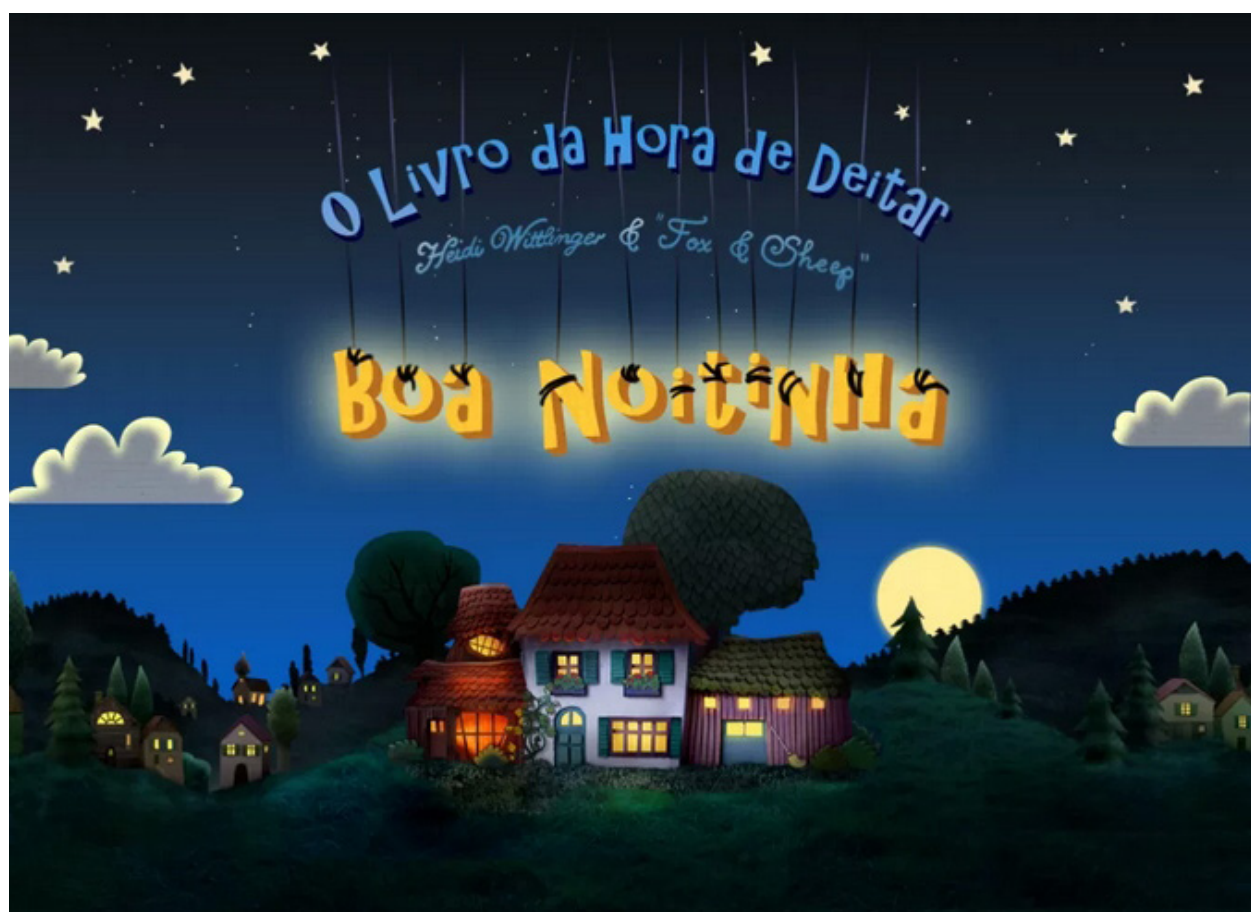

Fonte: Disponível em: https://play.google.com/store/apps/ details?id=com.foxandsheep.nightynight.

O segundo livro foi escolhido por ter uma alta quantidade de downloads. Ele se apresenta tanto como livro quanto como aplicativo de entretenimento. Além disso, está disponível para mais de um sistema operacional. O livro não é gratuito. Possui entre 10 e 50 mil instalações pelo sistema operacional Android e um feedback de quase 500 usuários com uma média de 4,4 estrelas 
(a avaliação permite pontuar até cinco). A versão foi atualizada mais de uma vez, sendo que a última foi no início de 2014.

A história é narrada, sem apoio de texto escrito. Isso indica que o livro foi pensado para crianças que ainda não leem. Apesar de apresentar oito diferentes línguas de narração, a tradução apresenta falhas e aparenta ser de um tradutor automático virtual, devido à artificialidade da fala.

O objetivo do livro é que o leitor apague as luzes de diversos cômodos de uma fazenda para adormecer os animais. Por fim, o livro sugere que o leitor deve também dormir. A interatividade está em conhecer cada cômodo, interagir com os animais e apagar as luzes.

Não há páginas, apenas oito cenas. Há possibilidade de observar a ilustração animada sem a narração. Não há trilha sonora, apenas alguns sons suaves e breves que indicam movimento dos animais ou o apagar das luzes pelo interruptor.

As ilustrações aparentam serem recortes manuais, fotografias e desenho digital de vetor e bitmap. Os elementos da cena que interagem são marcados com contraste de luz no objeto e sombra do fundo.

As cores nesse livro apresentam-se pouco iluminadas por ser um cenário noturno, porém com saturação, e há a constante presença de pontos luminosos nos cenários. A tipografia escolhida é sem serifa e só é vista no menu e créditos pois o livro não tem texto escrito, apenas falado.

\section{Vitória-Régia}

Figura 3- Tela do livro "Vitória-Régia"

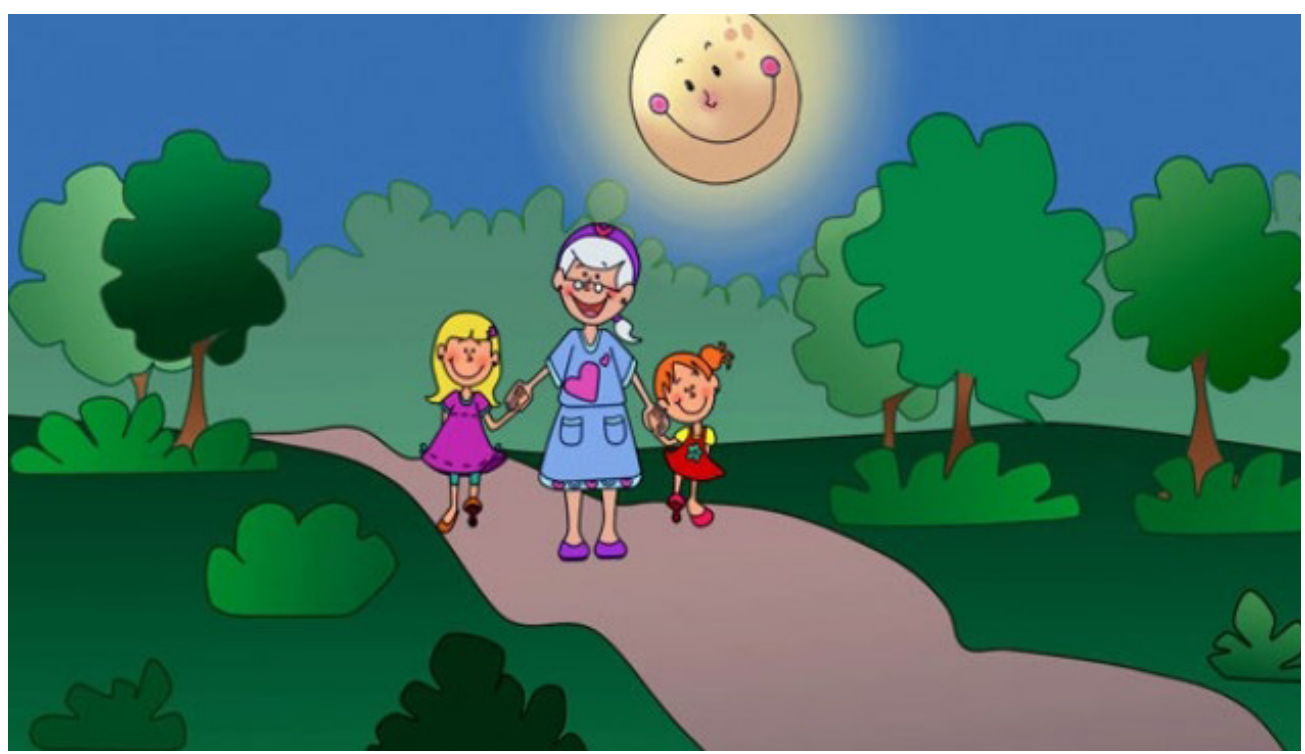

Disponível em: https://play.google.com/store/apps/details?id=br. 
Produzido pela empresa Cuca Maluca, o livro é também gratuito e nacional, e o motivo de ser escolhido para análise é por ter mais problemas gráficos, à primeira vista. Não tem atualizações desde seu lançamento, em 2012. Tem até cinco mil instalações e um feedback de apenas 21 usuários com uma média de 3,4 estrelas.

A história pode ser lida ou lida e escutada. O site informa que os livros são desenvolvidos para crianças de 2 a 10 anos de idade.

Sinopse: uma vovó conta para suas netas a história folclórica brasileira da transformação da índia Naiá na flor Vitória-Régia.

O livro tem 16 páginas. Não há nenhum tipo de interação ou interatividade a não ser a visualização de animações e escolha das cenas. Não há trilha sonora. Há, no menu, um espaço para jogos - a opção mais interativa do livro.

O livro é gratuito. A técnica de ilustração é digital em vetor, pouco complexa. As cores todas são vibrantes, e não existem elementos de destaque nos cenários. Os elementos de texto encontram-se nas mesmas páginas das ilustrações, entretanto texto e ilustração são independentes, separados.

É possível concluir que esse livro desconsidera as possibilidades de interatividade no momento de leitura, além de ter pouca preocupação gráfica na ilustração e diagramação.

\section{CONSIDERAC̣ÕES FINAIS}

O livro infantil digital apresenta-se como uma nova ramificação do livro infantil, e seu propósito não deve ser de substituir o livro impresso. Ele nada mais é que a transformação de um objeto que já existia. E apresenta características híbridas, além da de livro. Esse novo formato de livro infantil potencialmente desperta o interesse de crianças, pois os nativos digitais e absorvem rapidamente as informações apresentadas. Eles necessitam de diversos estímulos em pouco tempo para manter a atenção e continuarem se divertindo.

Se o livro infantil é identificado como tal a posteriori, entretanto, não é possível concluir tão rapidamente que os livros digitais apresentados aqui são prazerosos para as crianças. No entanto, é possível estabelecer se há uma funcionalidade e consideração estética que pode colaborar com o sucesso da proposta de leitura que entretém. 
É possível que o livro infantil digital aproxime-se ao formato de jogo devido à interatividade. Afinal, sem ela o livro não seria interessante: a interatividade já é quesito básico em aplicativos para telas com sensibilidade ao toque. Porém não há nisso um problema já que está estabelecido que este modelo de livro não substitui a literatura clássica.

Quanto aos livros apresentados, os dois primeiros têm boa qualidade gráfica e interatividade. Embora o resultado comercial não esteja visível no primeiro caso, o segundo mostra que há uma demanda e que, portanto, é possível que tal qualidade e preocupação gráfica e de atualização do aplicativo sejam muito responsáveis pelo interesse na compra.

O fato desses primeiros livros não serem gratuitos leva a crer que esse seja um fator pelo qual houve uma dedicação à apresentação visual dos livros. É necessário considerar que a amostra de livros analisada não é grande, pois uma pesquisa extensa não caberia ao objetivo e formato deste trabalho.

Assim, embora seja necessária uma pesquisa posterior e maior para esclarecer se há uma real aceitação desses livros por crianças e se elas o consideram ou não como prazerosos, já é possível concluir que o novo suporte de mídia traz para o designer gráfico uma nova área de estudo e atuação onde a visualidade é um dos elementos primordiais.

\section{REFERÊNCIAS}

AMBROSE, Gavin; HARRIS, Paul. Fundamentos de Design Criativo. São Paulo: Bookman, 2009. $176 \mathrm{p}$.

BERGSTRÖM, Bo. Fundamentos da Comunicação Visual. São Paulo: Rosari, 2010. $240 \mathrm{p}$.

BRINGHURST, Robert. Elementos do Estilo Tipográfico. São Paulo: Cosac Naify, 2005. $428 \mathrm{p}$.

COELHO, Nelly Novaes. Literatura infantil: teoria, análise, didática. 6. ed. São Paulo: Ática, 1997. 246 p.

COSENZA, Ramon M. Para atender os Nativos Digitais. Revista Pátio, n. 28, jul. 2011. Disponível em:<http://www.grupoa.com.br/revista-patio/artigo/5829/ para-atender-os-nativos-digitais.aspx>. Acesso em: 1 set. 2014. Entrevista concedida à revista. 
cores em comunicação. 5. ed. São Paulo: E. Blücher, 2006. 192 p.

FRASER, Tom; BANKS, Adam. O essencial da cor no design. São Paulo: SENAC, 2011. $256 \mathrm{p}$.

LINDEN, Sophie Van der. Para ler o livro ilustrado. São Paulo, Cosac Naify, 2011. $184 \mathrm{p}$.

LINS, Guto. Livro Infantil?: projeto gráfico, metodologia, subjetividade. São Paulo: Edições Rosari, 2003. 93 p.

LINS E SILVA, Patricia Konder. Os nativos digitais estão acostumados a uma interatividade diferente. Revolução eBook. Jun, 2013. Disponível em: $<$ http://revolucaoebook.com.br/ patricia-konder-lins-silva-nativos-digitaisestao-acostumados-uma-interatividade-diferente>. Acesso em: 1 set. 2014. Entrevista concedida a Eber Freitas.

MEIRELES, Cecília. Problemas da Literatura Infantil. 3. ed. Rio de Janeiro: Nova Fronteira, 1984. $120 \mathrm{p}$.

MELLO, Suely Amaral. Infância e Humanização: algumas considerações na perspectiva histórico-cultural. Revista Perspectiva, Florianópolis, v.25, n.1, p. 83104, jan/jul. 2007.

MORAES, Odilon. O projeto gráfico do livro infantil e juvenil. In: OLIVEIRA, leda de. O que é qualidade em ilustração no livro infantil e juvenil: com a palavra, o ilustrador. São Paulo: DCL, 2008. 214 p.

OLIVEIRA, Rui de. Pelos Jardins Boboli: reflexões sobre a arte de ilustrar livros para crianças e jovens. Rio de Janeiro: Nova Fronteira, 2008. 154 p.

PALO, Maria José; OLIVEIRA, Maria Rosa D. Literatura infantil: voz de criança. 4. ed. São Paulo: Ática, 2006. 80 p.

PEDROSA, Israel. O universo da cor. Rio de Janeiro: SENAC Nacional, 2004. 154 p.

PRENSKY, Marc. Digital Natives, Digital Immigrants. On the Horizon, Reino Unido, v.9, n.5, out. 2001a.

PRENSKY, Marc. Digital Natives, Digital Immigrants, Part II: Do they really think differently?.On the Horizon, ReinoUnido, MCB University Press, v.9, n.6, dez. $2001 b$. 
SHATZKIN, Mike. Livros infantis impressos x tablets. 2010. Disponível em: <http://www.publishnews.com.br/telas/colunas/detalhes.aspx?id=60810>. Acesso em: 1 set. 2014.

SILVEIRA, Luciana Martha. Cor, Design e Consumo. In: QUELUZ, Marilda L. P. (Org.). Design e Consumo. Curitiba: Peregrina, 2010. p. 35-48.

WILLBERG, Hans Peter; FORSSMAN, Friedrich. Primeiros Socorros em Tipografia. São Paulo: Rosari, 2007. 104 p. 